\title{
PERANCANGAN SISTEM PEWAKTUAN DAN PENGONTROLAN TEMPERATUR PADA APLIKASI KAMAR TEMPERATUR DENGAN SENSOR LM35DZ BERBASIS MIKROKONTROLER AT89S52
}

\author{
Muharmen Suari, Afdhal Muttaqin, dan Imam Taufik \\ Jurusan Fisika FMIPA Universitas Andalas
}

\begin{abstract}
ABSTRAK
Telah dirancang sistem kamar temperatur dengan pengaturan temperatur dan pewaktuan mengunakan mikrokontroler AT89S52 serta sensor temperatur LM35DZ sebagai pengindra temperaturnya. Perancangan ini terdiri dari perangkat keras (keypad 4x4, LCD, ADC0804, LM35DZ, penguat tak membalik, dan relay) dan perancangan perangkat lunak sistem kamar temperatur dengan bahasa pemograman C. Data hasil penelitian dianalisa mengunakan metode grafik dan teori error. Hasil analisa data menunjukan bahwa tegangan keluaran sensor LM35DZ sebanding dengan temperatur dengan sensitivitas $0,009 \mathrm{~V} /{ }^{\circ} \mathrm{C}$ dan nilai awal $0,041 \mathrm{~V}$. Penguatan rangkaian penguat tak membalik adalah sebesar 4,963 kali dengan nilai awal keluaran penguat sebesar $-0,005 \mathrm{~V}$. Perubahan temperatur yang indra sensor sebanding dengan data keluaran ADC0804 dengan kemiringan garis $0,402{ }^{\circ} \mathrm{C}$ dan nilai awal temperatur sebesar $-2,755{ }^{\circ} \mathrm{C}$. Temperatur dan lama pengaturan temperatur dapat diubah dari luar sesuai keinginan penguna.
\end{abstract}

Kata Kunci : ADC0804, AT89S52, LCD, LM35DZ, Keypad 4x4, Penguat tak membalik, Sistem kamar temperatur

\section{PENDAHULUAN}

Kamar temperatur merupakan suatu ruang di mana temperatur sistem terisolasi dari pengaruh temperatur lingkungan. Pada kamar temperatur yang telah terintegrasi, dapat ditambahkan pengontrolan waktu serta besaran fisis lainnya untuk menunjang kerja kamar temperatur sesuai kebutuhan. Sistem pengontrolan temperatur dapat dilakukan melalui sistem kontrol loop terbuka dan sistem kontrol loop tertutup (Bolton, 2006). Penelitian tentang sistem kontrol temperatur dalam suatu ruang telah dilakukan dalam berbagai aplikasi. Diantaranya peralatan penyimpan makanan oleh Lee dan Ryu (Lee, 1997) dan perancangan sistem untuk mengontrol dan meregulasi temperatur kamar pada suatu bangunan dengan memperkirakan daya pemanas dan daya pendingin yang digunakan oleh Gwerder (Gwerder, 2009).

Elemen pemanas sebagai piranti utama pada sistem kamar temperatur berguna untuk yang mengubah energi listrik menjadi energi panas. Apabila temperatur pada elemen pemanas semakin panas maka akan menaikkan resistansi pada elemen tersebut, yang berarti naiknya resistansi pada elemen meyebabkan penurunan arus pada elemen pemanas. Penurunan arus inilah yang akan menyebabkan adanya daya terdisipasi (energi yang hilang) menjadi panas. Oleh karena itu, untuk mendapatkan sistem yang mampu bertahan pada kondisi yang diinginkan dilakukan dengan pengaturan daya melalui arus masuk pada elemen pemanas. Hal umum yang biasanya dilakukan dalam pengaturan ini adalah pengaktifan dan penonaktifan elemen pemanas secara berkesinambungan dalam jangkauan temperatur yang diatur. Cara demikian tentu tidak efisien dan membebani biaya listrik, apalagi jika jangkauan temperaturnya kecil.

Penghematan dapat dilakukan dengan pengaturan daya bertingkat sesuai dengan perhitungan daya yang dibutuhkan. Jika sistem telah berada pada rentang temperatur yang diinginkan, maka digunakan daya rendah untuk mempertahankan sistem pada 
rentang temperatur tersebut. Ini dapat dilakukan dengan mengintegrasikan sistem elemen pemanas dengan suatu pembaca temperatur (sensor temperatur) (Lacanette, 1997, Tuite, 2008) yang di integrasikan dengan mikrokontroler(Asrizal, 2010, Winoto, 2008, Usman 2008, Hin, 2007, Widodo, 2009, Iswanto, 2008)

\section{METODE PENELITIAN}

Perancangan sistem pewaktuan dan pengontrolan temperatur pada kamar temperatur ini terdiri dari perancangan perangkat keras dan perancangan perangkat lunak. Perancangan perangkat keras terdiri dari bagian catudaya, sensor, penguat tak membalik, ADC 0804, LCD, keypad 4x4, dan rangkaian sistem saklar ke elemen pemanas yang dibuat dalam blok-blok rangkaian terpisah. Hal ini agar memudahkan dalam menemukan kesalahan jika sistem perancangan tidak berjalan optimal. Diagram blok sistem perancangan kamar temperatur ini dapat dilihat pada Gambar 1.

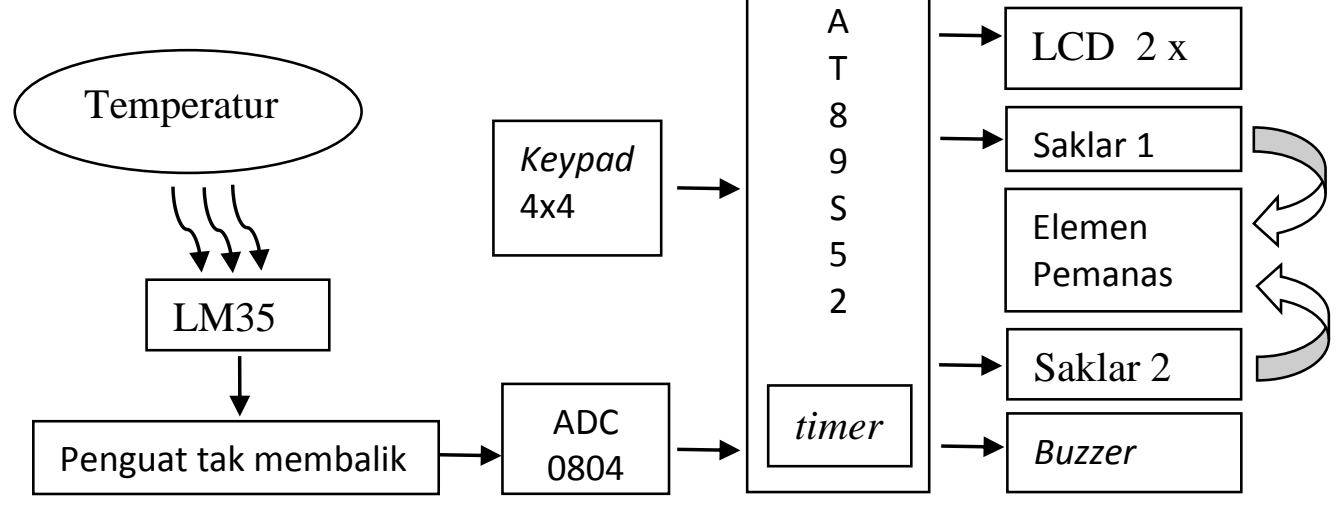

Gambar 1. Diagram blok sistem perancangan kamar temperatur

Perancangan perangkat lunak berkaitan dengan program yang diisikan pada mikrokontroler. Hal ini karena mikrokontroler tidak dapat mengendalikan alat lain, kecuali diprogram sesuai dengan pekerjaan yang akan dilakukannya. Pada penelitian ini digunakan bahasa pemograman C untuk memprogram mikrokontroler AT89S52. Sebelum program pengendalikan rangkaian dibuat maka dibutuhkan flowchart atau diagram alir program untuk menentukan langkah-langkah atau alur penulisan program yang akan diisikan pada mikrokontroler. Diagram alir program sistem perancangan kamar kamar temperatur yang akan dibuat dapat dilihat pada Gambar 2.

Sistem pengontrolan temperatur pada penelitian ini dilakukan secara digital dan otomatis. Temperatur ruangan akan diindra oleh sensor temperatur LM35DZ dan selanjutnya dikuatkan dengan penguat tak membalik dan kemudian akan dikonversi menjadi data digital oleh ADC0804 sehingga data pengindraan temperatur dapat diolah dan dibandingkan oleh mikrokontroler dengan data yang dimasukkan oleh penguna. Pengguna dapat memasukkan data temperatur dan waktunya langsung dengan penekanan angka yang sesuai melalui keypad. Selanjutnya mikrokontroler akan menampilkan data pengaturan temperatur dan waktu beserta data pengukuran temperatur ruang saat tersebut di LCD.

Cara kerja sistem ini diawali dengan mikrokontroler menerima input data dari penguna berupa data pengaturan temperatur dan waktunya melalui keypad dan selanjutnya ditampilkan ke LCD. Setelah menerima perintah jalankan dari penguna maka mikrokontroler akan melakukan pengontrolan temperatur dengan cara membandingkan 
data masukan temperatur dengan temperatur ruang yang terdeteksi oleh sensor. Untuk menjaga temperatur berada pada nilai batasnya maka digunakan dua buah relay dengan satu elemen pemanas (heater). Relay pertama dihubungkan dengan tegangan PLN 220V sedangkan relay kedua dihubungkan dengan tegangan yang lebih rendah sekitar $30 \mathrm{~V}$. Kedua sumber tegangan ini akan digunakan untuk mencatu heater secara bergantian. Saat pertama kali alat dijalankan maka yang dihidupkan adalah relay pertama sampai batas temperatur tercapai. Ketika batas temperatur tercapai maka timer dijalankan dan relay pertama dimatikan. Selanjutnya untuk mengontrol temperatur agar berada pada nilai yang diinginkan dapat diatur dengan menghidupkan atau mematikan relay kedua secara otomatis oleh mikrokontroler. Ketika waktu yang telah ditentukan sebelumnya oleh penguna sama dengan timer dari mikrokontroler maka mikrokontroler akan mematikan relay kedua serta membunyikan alarm ke penguna bahwa nilai temperatur dan waktunya telah tercapai.

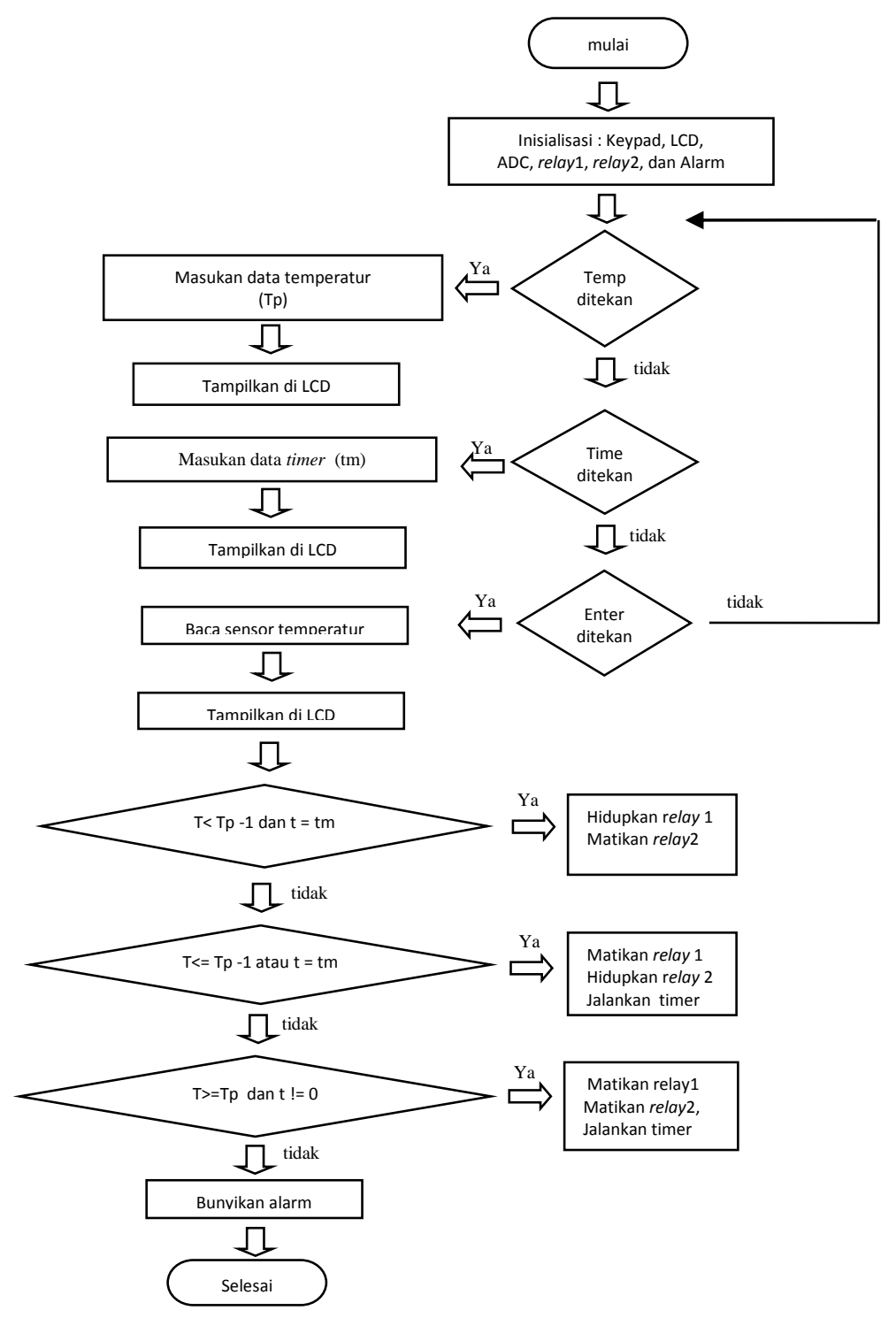

Gambar 2. Diagram alir program perancangan kamar temperatur 
Pengujian dilakukan antara lain: kalibrasi sensor temperatur LM35DZ (dengan membandingkan tegangan keluaran sensor terhadap hasil pembacaan termometer digital dan termometer air raksa), pengujian keypad 4x4 dan tampilan pada lcd dilakukan dengan menanamkan program pembacaan keypad dan led pada mikrokontroler dan melihat tampilan pada lcd sesuai dengan tombol penekanan keypad, pengujian rangkaian pembaca temperatur dilakukan secara bertahap. dimulai dari pengujian sensor temperatur, penguat tak membalik dan keluaran adc0804 yang dilakukan secara terpisah dan dilanjutkan pengujian sensor temperatur dengan tampilan pada lcd setelah dilakukan linierisasi terhadap keluaran adc0804, pengujian otomatisasi pewaktuan dengan mengunakan timer pada mikrokontroler dan membandingkannya dengan hasil pembacaan stopwatch digital, pengujian dan pengukuran laju perubahan temperatur terhadap variasi daya listrik pada elemen pemanas yang sama, dan pengujian otomatisasi dalam peaktifan relay pada elemen pemanas supaya sistem kontrol kamar temperatur ini dapat berjalan seperti yang diharapkanSetelah tahap-tahap penelitian di atas dilakukan maka dilanjutkan dengan pengujian keseluruhan sistem serta perancangan box kamar temperatur serta penempatan masing-masing blok rangkaian sehingga terbentuk sebuah sistem rangkaian yang utuh. Bentuk box rancangan kamar temperatur yang penulis buat adalah seperti pada Gambar 3.

Box kamar temperatur ini terdiri atas sebuah tabung berdiameter $14 \mathrm{~cm}$ dan tinggi $15 \mathrm{~cm}$

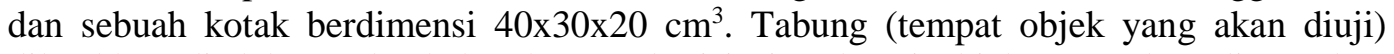
diletakkan di dalam sebuah kotak yang berisi air sebagai objek yang akan dipanaskan temperaturnya. Di dalam air ini dimasukkan sebuah heater yang berguna untuk memanaskan cairan. Sensor LM35DZ juga ditempatkan di dalam cairan tersebut. Dibagian luar kotak ada tempat meletakkan catu daya dan relay untuk melakukan pengontrolan temperatur serta LCD sebagai tampilan dan keypad sebagai tombol memasukkan data.

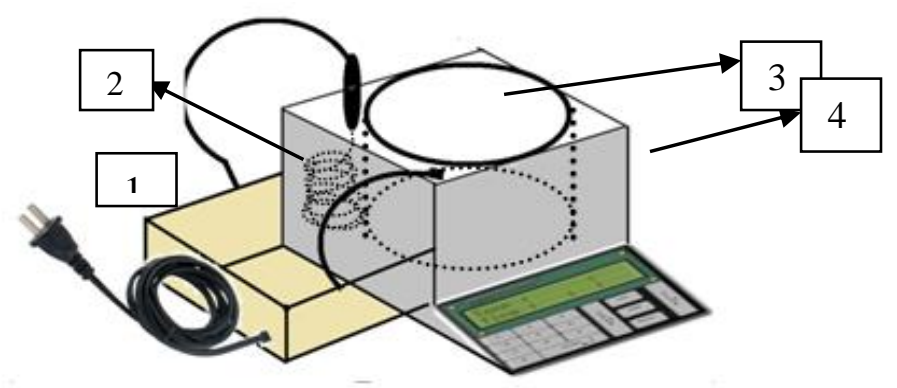

Gambar 3. Rancangan bentuk box kamar temperatur 1) kabel daya ke listrik pln, 2) kumparan pemanas (heater), 3) ruang kamar temperatur, 4) keypad dan LCD penampil

\section{HASIL DAN DISKUSI}

Untuk mengetahui apakah perangkat keras yang telah dirancang dapat bekerja atau berfungsi dengan baik sebagaimana yang diinginkan, maka dilakukan pengujian terhadap perangkat keras ini. Pengujian yang dilakukan terhadap perangkat keras meliputi pengujian masing-masing blok rangkaian dan pengujian terhadap gabungan dari masingmasing blok rangkaian tersebut.

\section{Pengujian Catu Daya}

Setelah dilakukan pengukuran maka didapatkan besar keluaran catudaya yang telah dirancang adalah sebesar 4,95 volt dan 8,93 volt. Keluaran tegangan catudaya tersebut masih dapat digunakan karena masih berada pada rentang tegangan yang diperlukan agar komponen-komponen tersebut dapat bekerja yaitu mikrokontroler (4V sampai 5,5 V), 
LM35DZ (4V sampai 30V), ADC0804(4,5V sampai 6,3V), dan LM324 (3,0V sampai $32 \mathrm{~V})$.

\section{Pengujian Sensor Temperatur LM35DZ}

Sensor temperatur LM35DZ memiliki rentang pembacaan temperatur dari $0{ }^{\circ} \mathrm{C}$ sampai $100{ }^{\circ} \mathrm{C}$. Pada perancangan ini digunakan air sebagai media pemanasnya sehingga temperatur yang dibaca sensor akan terbatas sampai titik didih air yaitu sekitar $100{ }^{\circ} \mathrm{C}$. Namun kaki-kaki LM35 sangat sensitif terhadap air sehingga kaki-kaki LM35 perlu diisolasi dari air. Pada perancangan ini kaki LM35 diisolasi dengan diberi perekat stainless steel dan dibiarkan mengering selama 24 jam. Perekatan LM35 ini akan mempengaruhi pembacaan sensor sehingga sensor ini perlu diuji sebelum digunakan. Pengujian sensor temperatur ini dilakukan dengan memasukan sensor LM35 dan termometer digital kedalam air yang ditambah pecahan batu ES yang kemudian dipanaskan di dalam cangkir listrik 400 watt. Daya 400 watt menghasilkan panas yang cukup cepat sehingga tidak dapat melihat perubahan temperatur pada termometer digital dan keluaran tegangan sensor LM35 pada multimeter digital. Agar pengukuran dapat dilakukan maka daya pada cangkir listrik itu perlu diturunkan dengan mengunakan dimmer. Grafik hubungan antara perubahan temperatur dan tegangan keluaran pada LM35 dapat dilihat pada Gambar 5.

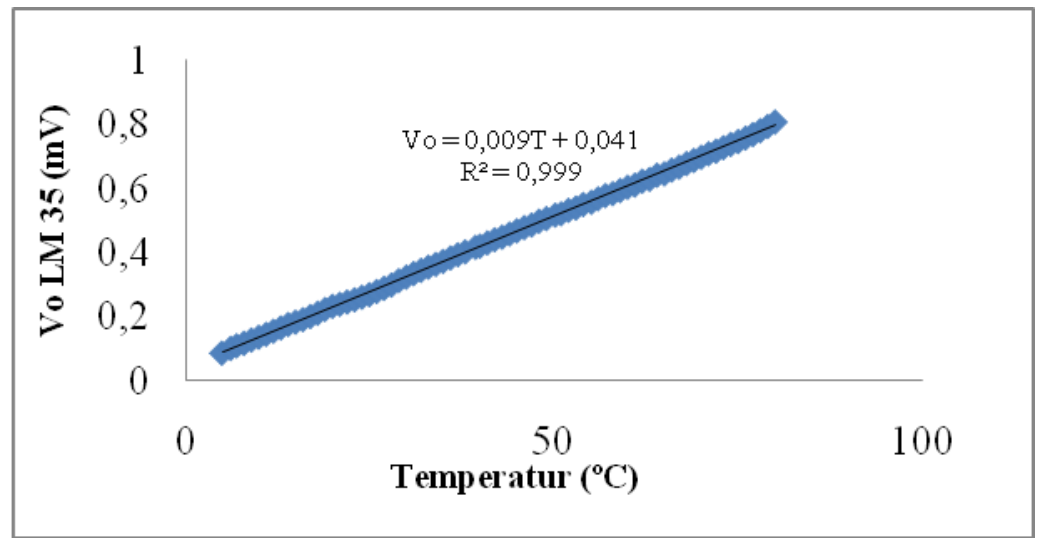

Gambar 5. Grafik hasil pengujian sensor LM35DZ

Dari persamaan dapat dijelaskan bahwa kenaikan tegangan keluaran sensor berbanding secara linear dengan kenaikan temperatur. Angka 0,009 volt $/{ }^{\circ} \mathrm{C}$ menyatakan sensitivitas dari sensor LM35, sedangkan angka 0,041 volt menyatakan tegangan keluaran awal dari sensor pada saat temperatur $0{ }^{\circ} \mathrm{C}$. Koefisien determinasi dari hubungan antara tegangan keluaran sensor dengan temperatur didapatkan $\mathrm{r}^{2}=0,999$. Hasil ini berarti 99,9\% variasi variabel terikat disebabkan oleh variabel bebas. Hasil ini telah mendekati nilai sensitivitas sensor yaitu sebesar $10 \mathrm{mV} /{ }^{\circ} \mathrm{C}$.

\section{Pengujian Rangkaian Penguat Tak Membalik (Non Inverting)}

Pengujian penguat tak membalik pada rangkaian ini dilakukan dengan cara memberikan variasi tegangan masukan penguat dengan mengunakan dua buah potensiometer. Potensiometer pertama dicatu dengan tegangan 4,95V dan diatur keluarannya sekitar $1 \mathrm{~V}$. Sedangkan potensiometer kedua dicatu oleh keluaran $1 \mathrm{~V}$ yang dihasilkan oleh potensiometer pertama. Keluaran potensiometer kedua ini akan diberikan ke masukan rangkaian penguat. Dengan memutar potensiometer kedua ini akan dihasilkan tegangan masukan dalam rentang $0 \mathrm{~V}$ sampai $1 \mathrm{~V}$. Dalam pengujian dilakukan pengambilan data untuk setiap perubahan tegangan masukan sebesar 0,05 volt dan kemudian diukur besar 
keluarannya mengunakan multimeter digital. Grafik hubungan antara tegangan masukan penguat dengan tegangan keluaran penguat dapat dilihat pada Gambar 6.

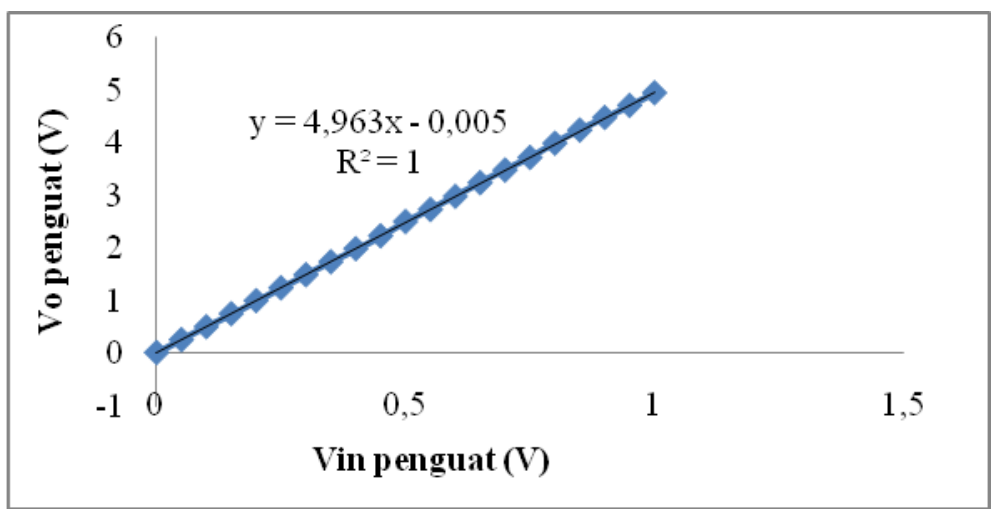

Gambar 6. Grafik hasil pengujian rangkaian penguat

Dari hasil tersebut terlihat bahwa hubungan antara masukan penguat dan keluaran penguat adalah linear. Hal tersebut terlihat dari korelasi linearnya 1. Dari grafik tersebut terlihat bahwa besar penguatan dari rangkaian penguat tersebut adalah 4,963 kali. Hasil tersebut sudah mendekati hasil penguatan yang diharapkan yaitu secara teori sebesar 5 kali. Perbedaan hasil tersebut disebabkan karena adanya pengaruh dari toleransi nilainilai resistor yang digunakan dalam penelitian ini.

\section{Pengujian rangkaian ADC 0804}

Sebelum melakukan pengujian rangkaian ADC, mikrokontroler diprogram terlebih dahulu untuk menampilkan data hasil pembacaan ADC0804. Setelah itu dilakukan pengujian ADC0804 dengan input masukan berasal dari potensiometer yang dicatu dengan tegangan $4,95 \mathrm{~V}$. Setelah itu dilihat besarnya tegangan pada multimeter untuk setiap kenaikan data desimal pembacaan ADC. Hasil pengujian ditampilkan dalam bentuk grafik hubungan antara tegangan dan data desimal.

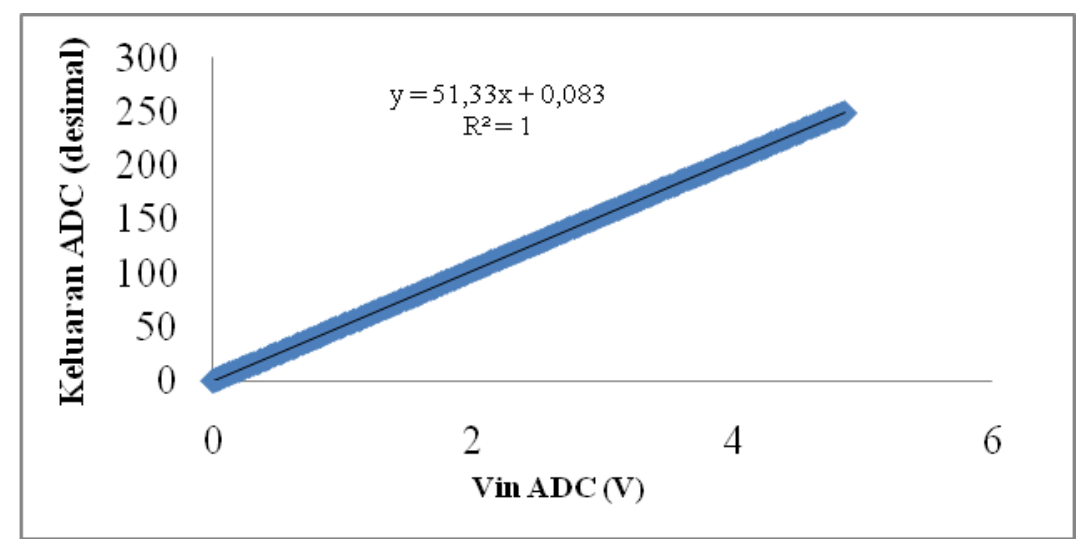

Gambar 7 Grafik hasil pengujian ADC 0804

Pengujian hasil pembacaan sensor dengan termometer digital 
Pengujian hasil pembacaan sensor ini dilakukan untuk melihat seberapa akuratnya tingkat ketelitian dari alat ini untuk mendeteksi temperatur dibandingkan dengan hasil pembacaan temperatur dari termometer digital. Hasil pengujian menunjukkan perbedaan yang kecil antara pembacaan termometer digital dengan tampilan pada LCD dengan persentase perbedaan berkisar antara $0,0 \%$ sampai dengan $2,82 \%$.

\section{Pengujian jam digital pada sistem pewaktuan}

Pengujian jam digital sebenarnya tidak dapat dilakukan secara tepat karena waktu merupakan suatu standar yang harus dikalibrasikan dengan standar waktu yang benar. Namun pengujian ini perlu dilakukan untuk melihat seberapa akurat dan presisi pewaktuan jam digital yang digunakan pada perancangan ini. Untuk itu maka pengujian dilakukan dengan membandingkan hasil timer pada tampilan LCD dengan stopwatch hp sebagai acuannya. Pengujian ini dilakukan dengan melihat tampilan pada jam di LCD setiap 60 detik dan dilihat beberapa detik terbaca pada stopwatch HP. Hasil pengujian jam digital menunjukkan perbedaan pembacaan hingga $0,72 \%$.

\section{Pengujian dan Pengukuran Laju Perubahan temperatur terhadap Variasi Sumber Tegangan pada Elemen Pemanas}

Pengujian ini diperlukan untuk melihat pengaruh perubahan daya listrik pada elemen pemanas terhadap laju perubahan temperatur sehingga diperoleh informasi berapa lamanya waktu yang dibutuhkan sehingga temperatur dapat berubah sebesar 1 derajat celsius untuk setiap perubahan daya listrik pada elemen pemanas. Pengujian ini dilakukan dengan mengunakan sebuah mug listrik 400 watt dan memanaskan air mulai dari temperatur kamar yaitu sekitar $27^{\circ} \mathrm{C}$. Untuk memvariasikan daya pemanas digunakan sebuah dimmer dengan daya maksimum 600 watt. Hasil pengujian dapat dilihat pada Tabel 1.

Tabel 1. Hasil pengujian pengaruh variasi sumber tegangan pada elemen pemanas terhadap laju perubahan temperatur.

\begin{tabular}{|c|c|c|c|}
\hline Tegangan $(\mathrm{V})$ & $\begin{array}{c}\text { Rentang T } \\
\left({ }^{\circ} \mathrm{C}\right)\end{array}$ & $\begin{array}{c}\Delta \mathrm{t} \\
(\mathrm{s})\end{array}$ & $\begin{array}{c}\text { laju perubahan temperatur } \\
\left({ }^{\circ} \mathrm{C} / \mathrm{s}\right)\end{array}$ \\
\hline 220 & $26,2-98,0$ & 1566 & 0,05260 \\
\hline 170 & $27,0-96,0$ & 2217 & 0,03112 \\
\hline 120 & $27,0-79,0$ & 4470 & 0,01163 \\
\hline
\end{tabular}

Dari tabel 1 terlihat semakin kecil tegangan yang diberikan pada elemen pemanas maka semakin kecil laju perubahan temperaturnya. Sehingga untuk dapat mempertahankan temperatur berada pada rentang temperatur yang lebih kecil dapat dilakukan dengan mengatur daya yang diberikan pada elemen pemanas.

\section{Pengujian Sistem Kamar Temperatur}

Pengujian sistem kamar temperatur ini dilakukan dengan mengunakan sebuah mug listrik dengan air terisi $3 / 4$ bagian mug. Pada pengujian sistem dapat berjalan sesuai dengan yang diinginkan sesuai dengan rentang temperatur yang diatur selama rentang waktu yang telah ditentukan. Saat pengujian data temperatur dimasukkan dengan keypad sebesar $45^{\circ} \mathrm{C}$ dan rentang waktunya sebesar 12 menit 44 detik. Ketika tombol enter ditekan maka langsung hidup dan memanaskan air sampai temperatur $44^{\circ} \mathrm{C}$. Lama waktu yang dibutuhkan untuk memanaskan air sampai $44{ }^{\circ} \mathrm{C}$ adalah 5 menit. Saat temperatur terbaca $44{ }^{\circ} \mathrm{C}$ maka relay pertama mati dan timer mulai dijalankan, dan secara bersamaan relay kedua dihidupkan 
sampai temperatur mencapai $45^{\circ} \mathrm{C}$. Lama waktu yang dibutuhkan untuk menaikan temperatur dari $44{ }^{\circ} \mathrm{C}$ sampai $45^{\circ} \mathrm{C}$ adalah selama 62 detik. Dan saat temperatur telah mencapai $45^{\circ} \mathrm{C}$ maka kedua relay dimatikan sehingga temperatur akan kembali turun. Saat temperatur mencapai $44{ }^{\circ} \mathrm{C}$ maka relay kedua dihidupkan kembali sehingga temperatur kembali naik. Waktu yang dibutuhkan menurunkan temperatur dari $45{ }^{\circ} \mathrm{C}$ menjadi $44^{\circ} \mathrm{C}$ adalah selama 58 detik. Demikian seterus sampai rentang waktu yang telah dimasukan tercapai.

Berdasarkan hasil pengujian kamar temperatur ini terlihat masih ada kelemahan pada alat yang dirancang yaitu dalam hal rentang temperatur pengunaan alat dan kecepatan alat dalam menghasilkan temperatur berada pada settingpoint nya. Temperatur tertinggi yang dapat diatur oleh penguna adalah sebesar $99{ }^{\circ} \mathrm{C}$. Nilai ini diperoleh dari nilai temperatur yang dapat ditampilkan alat pada LCD yaitu $99{ }^{\circ} \mathrm{C}$. Selain itu saat pengujian sensor temperatur LM35DZ ternyata sensor tidak dapat kembali turun ke temperatur kamar namun tetap berada pada nilai temperatur tertentu dalam waktu yang cukup lama, dalam pengujian yaitu sebesar $37^{\circ} \mathrm{C}$. Hal ini karena dampak perekatan sensor dengan lem stainless steel, dalam hal ini sensor mendeteksi panas dari lem ini sehingga temperatur yang dibaca sensor membutuhkan waktu yang lama untuk kembali ke temperatur kamar. Hal ini tentu saja berdampak pada batas minimum temperatur yang dapat diatur oleh penguna yaitu harus berada diatas temperatur $37^{\circ} \mathrm{C}$. Jika nilai $37^{\circ} \mathrm{C}$ merupakan saat relay pertama masih aktif maka berdasarkan program yang dituliskan pada alat, relay kedua akan aktif dari $38^{\circ} \mathrm{C}$ sampai $39^{\circ} \mathrm{C}$. Sehingga berdasarkan program yang dituliskan pada mikrokontroler didapatkan batas bawah temperatur adalah sebesar $39^{\circ} \mathrm{C}$. Berdasarkan analisa ini maka sistem perancangan kamar temperatur ini hanya dapat melakukan pengaturan temperatur dalam rentang $39^{\circ} \mathrm{C}$ sampai $99^{\circ} \mathrm{C}$.

Pada perancangan ini digunakan sebuah pemanas dengan daya 400 watt. Saat pemanas ini diberi tegangan $\mathrm{AC} 220 \mathrm{~V}$ maka temperatur akan naik dengan laju $0,053^{\circ} \mathrm{C} / \mathrm{detik}$ atau $3,16^{\circ} \mathrm{C} /$ menit. Temperatur dalam kamar temperatur ini akan naik secara perlahan sampai berada pada setting point temperatur yang diinginkan. Sehingga jika pengguna menginginkan temperatur harus berada pada setting point dalam waktu yang singkat maka alat ini kurang dapat dipergunakan. Agar alat ini dapat dipergunakan, elemen pemanas harus diganti dengan pemanas yang memiliki daya yang lebih besar. Namun hal ini tentu kurang dapat dilakukan karena dimmer yang digunakan dalam perancangan ini memiliki batas daya maksimum sebesar 600 watt. Sehingga daya maksimum elemen pemanas yang dapat digunakan sekitar 600 watt.

\section{KESIMPULAN}

Berdasarkan analisis data yang telah dilakukan dapat dikemukakan hasil dari penelitian ini, yaitu :

1. Tegangan keluaran sensor LM35DZ bertambah secara linier terhadap kenaikan temperatur dengan sensitivitas $0,009 \mathrm{~V} /{ }^{\circ} \mathrm{C}$ dan nilai awal $0,041 \mathrm{~V}$.

2. Tegangan keluaran dari penguatan tak membalik naik secara linier terhadap kenaikan tegangan masukan dengan penguatan sebesar 4,963 kali dan nilai awal tegangan keluaran sebesar $-0,005 \mathrm{~V}$.

3. Temperatur yang diindra sensor naik secara linier sebesar $0,402{ }^{\circ} \mathrm{C}$ untuk setiap kenaikan data hasil konversi ADC0804 dengan nilai awal temperatur sebesar -2,755 ${ }^{\circ} \mathrm{C}$. 
4. Temperatur hasil pembacaan sensor berubah secara linier sebesar 0,978 kali untuk setiap perubahan temperatur hasil pembacan temometer digital dengan nilai awal temperatur pembacaan sensor adalah $0,630{ }^{\circ} \mathrm{C}$.

5. Laju perubahan temperatur pada pemanas berdaya 400 watt dengan tegangan $\mathrm{AC} 220$ $\mathrm{V}$ adalah $0,0526{ }^{\circ} \mathrm{C} /$ detik dan menurun menjadi $0,0311^{\circ} \mathrm{C} /$ detik pada tegangan $\mathrm{AC}$ $170 \mathrm{~V}$ dan menjadi $0,0116^{\circ} \mathrm{C} /$ detik pada tegangan AC $120 \mathrm{~V}$.

6. Sistem kamar temperatur yang telah dirancang hanya mampu mengatur temperatur dalam rentang $39^{\circ} \mathrm{Csampai} 99^{\circ} \mathrm{C}$.

\section{REFERENSI}

1. Asrizal, 2010, Analisis Hubungan Besaran Fisika Pada Sistem Kontrol dengan Sensor PTAT Tipe IC LM 35 Berbasis Mikrokontroler AT89S51, Jurnal Eksakta Vol 1 tahun XI Februari 2010, UNP, Padang.

2. Bolton, W., 2006, Sistem Instrumentasi dan Sistem Kontrol, Erlangga, Jakarta.

3. Gwerder, M. dan Todtli, J., 2009, System for controling room temperature in building using predictive control, United States Patent Application Publication.

4. Hin, K., 2007, Pemograman Mikrokontroler PIC 16F84A, Andi Offset, Yogyakarta.

5. Iswanto, 2008, Antarmuka Port Paralel dan Port Serial dengan Delphi 6 Compatible Sistem Operasi Windows, Gava Media, Yogyakarta.

6. Lacanette, K., 1997, Temperatur Sensor Handbook, National Semiconductor Corporation.

7. Lee, Y. G. dan Ryu, B. G., 1997, Method for controling temperature in A Chamber of A food storage apparatus, United States Patent.

8. Tuite, D., 2008, Digital Temperature Sensors, Penton Media, Inc. All Rights reserved.

9. Usman, 2008, Teknik Antarmuka + Pemrograman Mikrokontroler AT89S52, Andi Offset, Yogyakarta.

10. Widodo, R. B., 2009, Embedded system mengunakan Mikrokontroler dan pemograman C, Andi Offset, Yogyakarta.

11. Winoto, A., 2008, Mikrokontroler AVR ATMEGA8/32/16/8535 dan Pemrogramannya dengan Bahasa $\mathrm{C}$ pada WinAVR, Informatika, Bandung. 